\title{
Oxidative stability of soybean oil added to coffee husk extract (Coffea arabica L.) under accelerated storage conditions
}

\author{
Elisa Franco RIBEIRO ${ }^{1}$, Neuza JORGE ${ }^{1 *}$
}

\begin{abstract}
Several plants have been studied as potential sources of natural antioxidants for use in the food industry, especially polyphenols. The aim of this study was to evaluate the effects of hydroalcoholic extract from coffee husk on the oxidative stability of soybean oil when stored in an oven. Samples were maintained at a temperature of $60^{\circ} \mathrm{C}$ and their oxidative stability was evaluated once every 5 days for a period of 20 days through the Rancimat equipament and analysis of peroxide value, conjugated dienes and tocopherols retention. The oxidation rate in terms of mass gain was evaluated once every 24 hours for a period of 24 days. Although the antioxidant TBHQ showed a better efficiency in the inhibition of oxidation, coffee husk extract showed a synergistic effect when used with the synthetic, delaying the appearance of degradation products. In addition, the freeze-dried extract showed the ability to reduce the mass-gain rate when used alone as well as when used in combination with the synthetic antioxidant butyl hydroxyanisole (BHA), noting a synergistic effect on oxidative stability between the extract and the BHA. Therefore, coffee husk extract could be considered a source of natural antioxidants for synthetic antioxidants substitution.
\end{abstract}

Keywords: vegetable oils; natural antioxidant; mass gain; agro-industrial waste; tocopherols.

Practical Applications: Coffee husks are a source of antioxidant compounds that can be extracted using environmentally-friendly processes, and finding uses for this agro-industry by-product also results in less waste.

\section{Introduction}

Lipid oxidation is one of the main deteriorative reactions that occur during food processing, distribution, storage, and preparation. Changes in lipid structures are responsible for affecting the nutritional value of food as well as its overall quality. Self-oxidation is a purely chemical phenomenon involving radical reactions capable of self-propagation, depending on the type of catalytic action such as temperature, metal ions, free radicals, and $\mathrm{pH}$ (Soares, 2002).

The high polyunsaturated fatty acid content of vegetable oils is what makes this food product so beneficial to human health. This nutritional value is due to the presence of essential fatty acids such as linoleic (omega 6) and linolenic (omega 3 ). However, there are concerns about the impact of technology on vegetable oil production and storage processes, as oxidative reactions may be more likely to occur (Hui, 1996).

In order to avoid lipid oxidation, it is necessary to minimize the incidence of factors responsible for the formation of free radicals such as temperature, light, and metallic traces, and it is also essential to prevent any contact with oxygen.

In addition to the control of interferences, the formation of free radicals can be blocked using antioxidants, which are able to slow down reactions or extend the induction period, delaying or even inhibiting oxidation reactions (Jorge \& Gonçalves, 1998).
The most commonly used synthetic antioxidants are butyl hydroxyanisole (BHA), butyl hydroxytoluene (BHT), propyl gallate (PG), and tert-butyl hydroquinone (TBHQ). These compounds have a phenolic structure, which allows the donation of a proton to a free radical, regenerating the acylglycerol molecule and interrupting the propagation of the oxidation reaction (Zhang et al., 2004). However, research has shown a potential carcinogenic effect on the health of individuals who frequently consume foods containing these additives (Venskutonis, 2013).

Society's growing demand for products that contribute to improving the quality of life has driven the search for bioactive substances from natural sources with antioxidant potential. The aim is to reduce the presence of synthetic antioxidants in food by substituting them or encouraging their use in combination with effective natural alternatives.

Natural antioxidants can be found and isolated from many plants: grain, seeds, cereals, nuts, fruits, vegetables, and spices are sources of natural antioxidants already reported (Jorge, 2009). A variety of agro-industrial by-products have been studied as attractive sources of natural antioxidants, such as potato peel, seeds, grapefruit peel, and coffee husks. Proteins, peptides, and products from Maillard reaction were also reported as antioxidant agents (Moure et al., 2001). 
Coffee (Coffea arabica) represents a food with relevant phenolic compositions. Chlorogenic acids appear in concentrations ranging from $6 \%$ to $10 \%$ of the beans' dry weight (Sánchez-González et al., 2005). According to Soccol (2002), the coffee pulp presents $42 \mathrm{mg} / 100 \mathrm{~g}$ of chlorogenic acid and $1,000 \mathrm{mg} / 100 \mathrm{~g}$ to $2,000 \mathrm{mg} / 100 \mathrm{~g}$ of ferulic acid.

Given the high generation of waste products containing potentially useful bioactive compounds and the interest in replacing synthetic antioxidants with natural ones, the aim of the present study was to evaluate the antioxidant potential of coffee husk extract added to soybean oil under accelerated storage conditions.

\section{Materials and methods}

\subsection{Obtaining and preparing the raw materials}

Coffee husks (Coffea arabica L.) resulting from dry processing methods were collected from local producers in the south of Minas Gerais, Brazil. The husks were lyophilized using a freeze dryer (model L-101, Liotop, São Carlos-SP, Brazil) at an approximate pressure of $200 \mu \mathrm{mHg}$ and at a temperature of $-50^{\circ} \mathrm{C}$. After the freeze-drying was complete, the husks were then pulverized using a domestic blender.

To obtain the extract, $20 \mathrm{~g}$ of pulverized coffee husks were added to $100 \mathrm{~mL}$ of hydroalcoholic solvent at a ratio of 1:1 (v/v). The material was shaken at 14,000 rpm for 2 minutes in an ultra-turrax (model T25, Ika, Staufen, Germany) with the assistance of a model $\mathrm{S} 25 \mathrm{~N}$ probe. Next, the material was put in an ultrasonic bath (model 740D, Ultrasonic Cleaner, Ribeirão Preto-SP, Brazil) for a 40-minute ice bath, and then it was spun in a centrifuge (model 206 MP, Excelsa II, São Paulo, Brazil) at $3,500 \mathrm{rpm}$ for 10 minutes. The supernatant was filtered using a Whatman $\mathrm{n}^{\circ} 4$ paper filter and lyophilized to remove the solvent.

The total phenolic content of the husks was previously determined using spectrophotometric methods with Gallic acid (GA) as standard curve, using methodology proposed by Singleton \& Rossi (1965), and the result was $12.94 \mathrm{mg} \mathrm{GAE/g}$ extract. Based on the extract's total phenolic content, $200 \mathrm{mg} / \mathrm{kg}$ was added to the soybean oil.

The experimental assays were performed with refined soybean oil containing no synthetic antioxidants. The synthetic antioxidants tert-butylhydroquinone (TBHQ) and butyl hydroxyanisole (BHA) supplied by Danisco A/S were used for comparison with the antioxidant effect of coffee husks.

\subsection{Experimental testing}

The following treatments were subjected to an accelerated storage test: Control (soybean oil without antioxidants), TBHQ (soybean oil $+200 \mathrm{mg} / \mathrm{kg}$ of TBHQ), BHA (soybean oil + $200 \mathrm{mg} / \mathrm{kg}$ of BHA), CE (soybean oil $+200 \mathrm{mg} / \mathrm{kg}$ of coffee husk extract), $\mathrm{BHA}+\mathrm{CE}$ (soybean oil $+100 \mathrm{mg} / \mathrm{kg}$ of BHA+ $100 \mathrm{mg} / \mathrm{kg}$ of coffee husk extract), and TBHQ + CE (soybean oil $+100 \mathrm{mg} / \mathrm{kg}$ of TBHQ $+100 \mathrm{mg} / \mathrm{kg}$ of coffee husk extract). The samples were stored in a heated oven at $60^{\circ} \mathrm{C}$ for 20 days, using $100 \mathrm{~mL}$ beakers containing $60 \mathrm{~mL}$ of the corresponding sample with a surface/volume ratio of $0.4 / \mathrm{cm}$. All the samples were collected at different time intervals ( $0,5,10,15$, and 20 days), and they were kept inert with nitrogen gas and stored at $-18{ }^{\circ} \mathrm{C}$ for further analysis.

\subsection{Oxidative stability}

The oxidative stability was determined using Cd 12b-92 method of AOCS (American Oil Chemists' Society, 1993) which is based on the determination of electrical conductivity of volatile degradation products using Rancimat (model 745, Metrohm, Herisau, Switzerland). The determination was performed at $100{ }^{\circ} \mathrm{C}$, with an airflow of $20 \mathrm{~L} / \mathrm{h}$, using $3 \mathrm{~g}$ of the sample and $60 \mathrm{~mL}$ of distilled water in the flasks containing electrodes. Curves of electrical conductivity versus time were recorded during the reaction and the induction period was expressed in hours.

\subsection{Peroxide value}

The peroxide value refers to all substances that oxidize potassium iodide (KI), calculated as miliequivalents of active oxygen per kilogram of fatty matter. This value was determined according to COC 8-53 of AOCS (American Oil Chemists' Society, 2009) through the iodine released in the reaction of potassium iodide with the peroxides present in the oil.

\subsection{Conjugated dienes}

The determination of conjugated dienes present in the fatty matter was carried out according to the Ti 1a-64 method of AOCS (American Oil Chemists' Society, 2009). The sample absorbance was read at $233 \mathrm{~nm}$ and the result was expressed as a percentage of conjugated dienoic acids.

\subsection{Mass gain}

The rate of oxidation, in terms of increases in mass, was recorded through direct weighing at 24 -hour intervals for 24 days. For mass-gain analysis, $2.0 \mathrm{~g}$ of each sample was placed in glass Petri dishes, which were kept in an oven at $60{ }^{\circ} \mathrm{C}$. The time required for the oil to increase in mass by $0.5 \%$ was taken as the index of stability and the increase in mass was calculated as a percentage of the original weight (Iqbal \& Bhanger 2007).

\subsection{Tocopherols}

The chromatographic analysis of tocopherols was performed according to the AOCS method Ce 8-89 (American Oil Chemists' Society, 2009), using a high efficiency liquid chromatograph (Varian brand, model 210-263, Walnut Creek-CA), equipped with a fluorescence detector. According to the conditions of the analysis, it was used the silica column of $250 \times 4.6 \mathrm{~mm}$ with pores of $5 \mu \mathrm{m}$, flow of $1.2 \mathrm{~mL} / \mathrm{min}$, excitation wavelength at $290 \mathrm{~nm}$ and emission at $330 \mathrm{~nm}$ and as the mobile phase the mixture of 99.5\% n-hexane and $0.5 \%$ isopropanol, all with purity for high performance liquid chromatography (HPLC). The tocopherols were identified by comparison with the retention time of the standards Sigma 95\% purity and were quantified by external standard and, thus, the tocopherol contents expressed in terms of $\mathrm{mg} / \mathrm{kg}$. 


\subsection{Statistical analysis}

The results obtained from analytical determinations in triplicate were subjected to analysis of variance to determine the effects of the treatments and the heating times on the changes in the oils that were subjected to the accelerated storage test. Thermal oxidation was measured using factorial design, with a completely randomized design. Both the analysis of variance and the Tukey test for the 5 percent average were obtained using STATISTIC software, version 10.0 (StatSoft Inc, Tulsa, EUA).

\section{Results and discussion}

\subsection{Oxidative stability}

The oxidative stability of the samples stored in an oven at $60^{\circ} \mathrm{C}$ for 20 days is shown in Figure 1. There was a reduction in the soybean oil's stability throughout the heating time in all samples. The coffee husk extract showed similar behavior to the BHA antioxidant and Control, however, the greatest stability after 10 days of storage following the induction period was found to be $4.37 \mathrm{~h}$ for CE, $2.96 \mathrm{~h}$ for Control, and $3.49 \mathrm{~h}$ for BHA.

The TBHQ antioxidant was the most efficient during the accelerated oxidation period induced through heating and the presence of oxygen. When CE was used together with TBHQ, there was a slight variation among the induction periods with no significant differences between 0 and 5 days and between 10 and 15 days. In this sample a synergistic effect was identified during the 15 days of storage, since the induction period did not

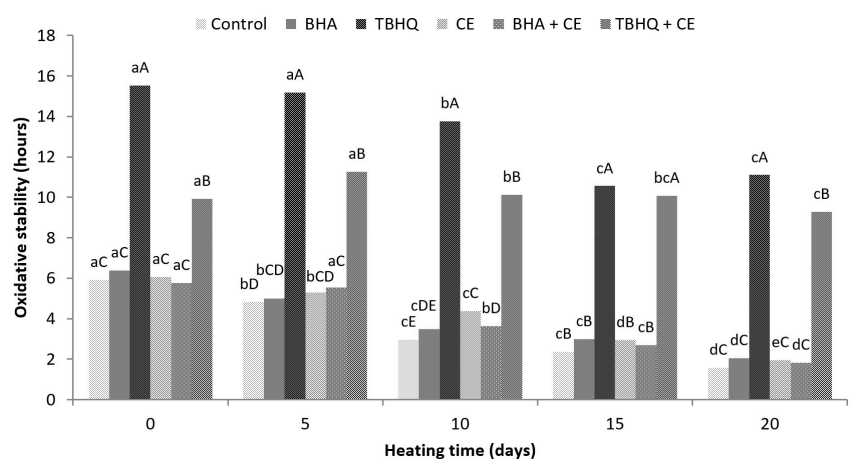

Figure 1. Oxidative stability (h) of the treatments subjected to accelerated storage conditions at $60^{\circ} \mathrm{C}$ for 20 days. Different lowercase letters for the same treatment indicate statistical difference by Tukey $(\mathrm{p} \leq 0.05)$. Different capital letters for the same time indicate statistical difference by Tukey $(\mathrm{p} \leq 0.05)$. differ significantly from the sample in which the TBHQ was used at the concentration of $200 \mathrm{mg} / \mathrm{kg}$.

Some of the coffee compounds such as caffeic, protocatechinic, p-hydroxybenzoic, ferulic, and p-coumaric acids were evaluated by Gadow et al. (1997) in relation to the oxidative stability of lard in concentrations of $200 \mathrm{mg} / \mathrm{kg}$, using Rancimat at $100^{\circ} \mathrm{C}$. In this study, caffeic and protocatechinic acids were found to perform better as antioxidants than BHT in the same concentrations.

The results obtained in the present study are aligned with those found in research into the antioxidant qualities of spices. Ravelli (2011) reported that the induction periods of soybean oil added to $100 \mathrm{mg} / \mathrm{kg}$ of total phenolic compounds from oregano and marjoram extracts were $6.80 \mathrm{~h}$ and $7.20 \mathrm{~h}$ respectively. The author also pointed out that adding hydroalcoholic extracts from rosemary, sage, and thyme to soybean oil had no significant antioxidant effect in relation to the Control sample. However, in this work it was also reported that TBHQ was the antioxidant that provided greater stability to soybean oil against oxidation catalyzed by high temperatures.

\subsection{Peroxide value}

Peroxides are the main primary oxidation products, since high amounts of peroxides consist of low oxidative stability (Yang et al., 2016). Table 1 shows that there was an increase in the peroxide value for all treatments during 20 days of storage. The use of BHA did not provide inhibition or reduction in the formation of peroxides to soybean oil, since the treatment with the antioxidant significantly differed from the control only in 10 days of accelerated heating.

The coffee husk extract provided to soybean oil a lower amount of peroxides formed compared to the BHA treatment. When this synthetic antioxidant was used together with the natural extract, a synergistic behavior was observed, since the amount of peroxides was lower than that found in the treatment with BHA only.

The amount of peroxides formed in the TBHQ treatment was lower than all treatments, except for the TBHQ + CE during the whole storage period. Thus, the synergistic effect was also observed between the coffee husk extract and the antioxidant TBHQ. The natural extract could reduce the formation of the primary oxidation products, obtaining values similar to those found by the treatment with only the synthetic antioxidant within the first 5 days of storage. The National Agency of Sanitary Surveillance (ANVISA) recommends a maximum of $10 \mathrm{meq} / \mathrm{kg}$ of peroxide value for refined soybean oil (Brasil, 2005). Thus, in

Table 1. Peroxide value (meq $/ \mathrm{kg})$ of samples under accelerated storage.

\begin{tabular}{|c|c|c|c|c|c|}
\hline \multirow{2}{*}{ Treatments } & \multicolumn{5}{|c|}{ Heating time (days) } \\
\hline & 0 & 5 & 10 & 15 & 20 \\
\hline Control & $1.20 \pm 0.29^{\mathrm{eAB}}$ & $5.94 \pm 0.14^{\mathrm{dA}}$ & $44.42 \pm 0.28^{\mathrm{cB}}$ & $65.70 \pm 0.89^{\mathrm{bA}}$ & $92.55 \pm 2.71^{\mathrm{aA}}$ \\
\hline BHA & $2.01 \pm 0.28^{\mathrm{eA}}$ & $6.44 \pm 0.84^{\mathrm{dA}}$ & $48.34 \pm 0.71^{\mathrm{cA}}$ & $65.36 \pm 0.23^{\mathrm{bA}}$ & $94.97 \pm 0.14^{\mathrm{aA}}$ \\
\hline TBHQ & $0.50 \pm 0.42^{\mathrm{cB}}$ & $1.80 \pm 0.27^{\mathrm{bc}}$ & $2.11 \pm 0.14^{\mathrm{bE}}$ & $2.41 \pm 0.00^{\mathrm{bD}}$ & $3.37 \pm 0.00 \mathrm{aD}$ \\
\hline $\mathrm{CE}$ & $0.90 \pm 0.14^{\mathrm{e}, \mathrm{B}}$ & $2.81 \pm 0.29 \mathrm{dBC}$ & $23.92 \pm 0.28^{\mathrm{cD}}$ & $54.62 \pm 0.08^{\mathrm{bc}}$ & $74.15 \pm 0.10^{\mathrm{aC}}$ \\
\hline $\mathrm{BHA}+\mathrm{CE}$ & $1.10 \pm 0.14^{\mathrm{eAB}}$ & $3.81 \pm 0.02 \mathrm{~dB}$ & $40.66 \pm 0.77^{c C}$ & $61.75 \pm 0.05^{\text {ьв }}$ & $87.54 \pm 0.14$ aв \\
\hline $\mathrm{TBHQ}+\mathrm{CE}$ & $0.80 \pm 0.28^{\mathrm{cB}}$ & $1.71 \pm 0.43^{\mathrm{bcC}}$ & $2.31 \pm 0.14^{\mathrm{abE}}$ & $2.71 \pm 0.14^{\mathrm{abD}}$ & $3.51 \pm 0.42^{\mathrm{aD}}$ \\
\hline
\end{tabular}

Different lowercase letters for the same treatment indicate statistical difference by Tukey ( $\mathrm{p} \leq 0.05)$. Different capital letters for the same time indicate statistical difference by Tukey ( $\mathrm{p} \leq 0.05$ ). 
the present study, all treatments were efficient until the 5th day, and this efficiency was maintained for the treatments TBHQ and TBHQ + CE throughout the storage period.

Zhang et al. (2010) evaluated the oxidative stability of sunflower oil added to rosemary extracts. This study showed that the peroxide value increased linearly with storage time, reaching a maximum of $272 \mathrm{meq} / \mathrm{kg}$ in 21 days for the Control. Although it presented higher values than the present work, the behavior of the antioxidants in this study was similar. The rate of peroxide formation was reduced when it were used the rosemary extract and the synthetic antioxidants BHA and TBHQ, which obtained values of 75.7, 205.0 and $20.0 \mathrm{meq} / \mathrm{kg}$, respectively, at the end of storage.

\subsection{Conjugated dienes}

Conjugated dienes, as well as peroxides, are the primary products of the oxidation of polyunsaturated fatty acids, formed by the displacement of double bonds.

Table 2 shows that, for Control, BHA, CE and BHA + CE, there was an increase in the number of conjugated dienes formed after 5 days of storage, with no significant difference between the treatments during the first 5 days. Although at the end of the storage the CE have obtained values similar to those found for the Control and for the BHA + CE, the coffee husk extract presented a difference of $45.83 \%$ in relation to the Control in 10 days of heating.

The TBHQ was the most efficient treatment, in which was observed a reduction of $62.83 \%$ of the conjugated dienes in relation to the Control. This value corresponds to that found by Silva \& Jorge (2012) in a study with mushrooms, in which it was reported a reduction of $65.42 \%$ of the compounds in relation to the Control. In addition, the use of the synthetic antioxidant TBHQ with the extract allowed stability in the formation of the compounds during the whole storage, obtaining a reduction of $68.24 \%$ at the end of the period. Similarly to the peroxide value, the synergistic effect between natural and synthetic extract was verified, since there was no difference between the treatments TBHQ and TBHQ + CE.

\subsection{Mass gain}

The oxidation rate, in terms of increases in mass, was used to estimate the amount of oxygen added to the unsaturated molecules of the lipid sample and also to monitor the formation of hydroperoxides during oxidation.
As shown in Figure 2, the time required for a $0.5 \%$ increase in mass was 5 days for BHA, 12 days for Control and CE, 14 days for $\mathrm{BHA}+\mathrm{CE}$, and 19 days for TBHQ + CE. The TBHQ antioxidant was the most efficient antioxidant in relation to the percentage of mass acquired, reaching a maximum of $0.37 \%$ increase in mass after 12 days of storage.

The coffee husk extract (CE) contributed to a later onset of mass gain than that demonstrated by the antioxidant BHA, assuming a greater mass gain in 17 days, at $4.01 \%$. In addition, the CE showed a synergistic effect with both BHA and TBHQ, showing, with the latter, a similar effect to that acquired by soybean oil added to TBHQ alone.

A decline was observed in all the treatments after reaching their maximum mass increase. This is due to the fact that the primary products of oxidation formed during the accelerated storage period can be degraded into low molecular weight compounds and also into volatile substances.

The mass gain of soybean oil added to mushroom extracts stored at $60^{\circ} \mathrm{C}$ was evaluated by Silva \& Jorge (2014). The author verified adding Lentinula edodes extract to soybean oil provided effective protection against oxidation during the first 11 days of storage, reaching the maximum increase of $4.05 \%$ after 13 days. In the same study, Agaricus blazei extract proved to be more efficient at protecting the oil as it continued to do so until the 15th day and TBHQ showed no significant increase until the 13th day.

According to Hinneburg et al. (2006), phenolic substances have been identified as being responsible for the antioxidant activity of plants. Phenolic compounds are the group of primary antioxidants that act by interrupting the chain reaction through

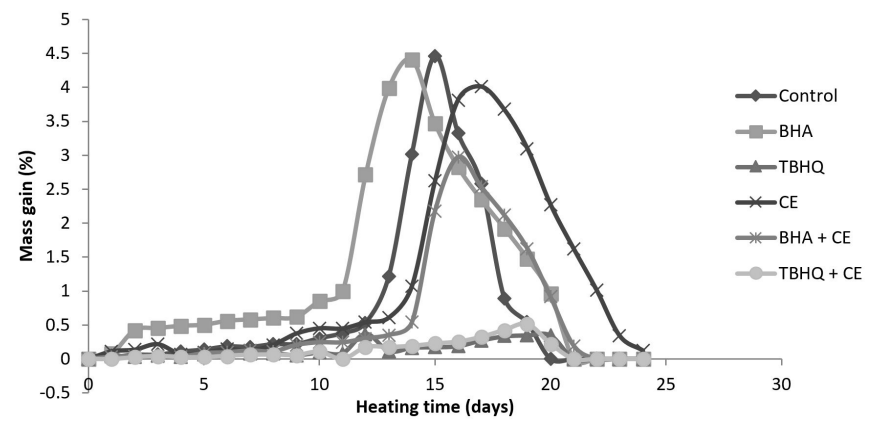

Figure 2. Oxidation rate in terms of mass gain of the treatments subjected to accelerated storage in an oven.

Table 2. Conjugated dienes (\%) of samples under accelerated storage.

\begin{tabular}{|c|c|c|c|c|c|}
\hline \multirow{2}{*}{ Treatments } & \multicolumn{5}{|c|}{ Heating time (days) } \\
\hline & 0 & 5 & 10 & 15 & 20 \\
\hline Control & $0.42 \pm 0.01^{\mathrm{cA}}$ & $0.48 \pm 0.04^{\mathrm{cA}}$ & $0.96 \pm 0.11^{\mathrm{bA}}$ & $0.91 \pm 0.03^{\mathrm{bB}}$ & $1.48 \pm 0.05^{\mathrm{aB}}$ \\
\hline BHA & $0.39 \pm 0.01 \mathrm{dA}$ & $0.47 \pm 0.02 \mathrm{dA}$ & $0.79 \pm 0.03^{\mathrm{cAB}}$ & $1.52 \pm 0.04^{\mathrm{bA}}$ & $1.77 \pm 0.02^{\mathrm{aA}}$ \\
\hline TBHQ & $0.41 \pm 0.01^{\mathrm{bA}}$ & $0.40 \pm 0.02^{\mathrm{bA}}$ & $0.38 \pm 0.02^{\mathrm{bD}}$ & $0.41 \pm 0.02^{\mathrm{bC}}$ & $0.55 \pm 0.01 \mathrm{aC}$ \\
\hline $\mathrm{CE}$ & $0.41 \pm 0.01^{\mathrm{cdA}}$ & $0.38 \pm 0.04 \mathrm{dA}$ & $0.52 \pm 0.02^{\mathrm{cCD}}$ & $0.86 \pm 0.03^{\text {bв }}$ & $1.38 \pm 0.06^{\mathrm{ab}}$ \\
\hline $\mathrm{BHA}+\mathrm{CE}$ & $0.41 \pm 0.02 \mathrm{dA}$ & $0.43 \pm 0.01 \mathrm{dA}$ & $0.70 \pm 0.02^{\mathrm{cBC}}$ & $0.87 \pm 0.02^{\mathrm{bB}}$ & $1.44 \pm 0.02^{\mathrm{aB}}$ \\
\hline
\end{tabular}

Different lowercase letters for the same treatment indicate statistical difference by Tukey $(\mathrm{p} \leq 0.05)$. Different capital letters for the same time indicate statistical difference by Tukey $(\mathrm{p} \leq 0.05)$. 
the transfer of hydrogen or electrons to free radicals, transforming them into stable and inactive products for the propagation of reactions (Araújo, 2006). Although synergists perform little or no antioxidant activity, they are able to increase the activity of primary antioxidants when used in suitable combinations (Ramalho \& Jorge, 2006).

\subsection{Tocopherols}

Determining the retention of tocopherols in soybean oil is a way of monitoring oil quality, since they are important components for the prevention of lipid oxidation. Table 3 shows the contents of the tocopherol isomers were higher for Control at day 0 , followed by $\mathrm{CE}$, presenting a significant reduction during the heating. The $\beta$-tocopherol isomer was not detected by the analysis.

The contents of $\alpha$-tocopherol and $\delta$-tocopherol showed good retentions by the treatment TBHQ + CE during the first 10 days of storage, since the concentrations did not differ significantly throughout the period. After this time, TBHQ was the only treatment that remained constant for the three isomers. Among the tocopherol isomers, the most stable was $\gamma$-tocopherol protected by the TBHQ + CE, in which it presented reduction of only
7.09\% in relation to its initial content. Although a-tocopherol showed higher susceptibility to oxidation for Control, BHA, $\mathrm{EC}$ and $\mathrm{BHA}+\mathrm{CE}$, the treatment $\mathrm{TBHQ}+\mathrm{CE}$ also effectively protected this isomer, with a reduction of $8.95 \%$ of its initial concentration. Studying the antioxidant activity of mushrooms by Silva \& Jorge (2014), it was also reported that $\alpha$-tocopherol was the least resistant isomer to the storage period. On the other hand, the mushroom extract and the synthetic antioxidant TBHQ could be effective in protecting the $\beta, \gamma$ and $\delta$-tocopherol isomers, remaining constant throughout the heating.

The use of $100 \mathrm{mg} / \mathrm{kg}$ of TBHQ with $100 \mathrm{mg} / \mathrm{kg}$ of husk extract provided better protection to all isomers compared to treatment where TBHQ was applied at the concentration of $200 \mathrm{mg} / \mathrm{kg}$. For total tocopherol contents, it was found that the protective properties were more effective for TBHQ + CE followed by TBHQ, with a reduction of 7.29 and $27.13 \%$, respectively.

Thus, it was verified that the addition of the coffee husks extract acted in synergy with the synthetic antioxidant TBHQ in the protection of tocopherols present in soybean oil, and $\gamma$-tocopherol was the most effective antioxidant in preventing the degradation of tocopherols.

Table 3. Averages of tocopherols contents $(\mathrm{mg} / \mathrm{kg})$ of samples under accelerated storage.

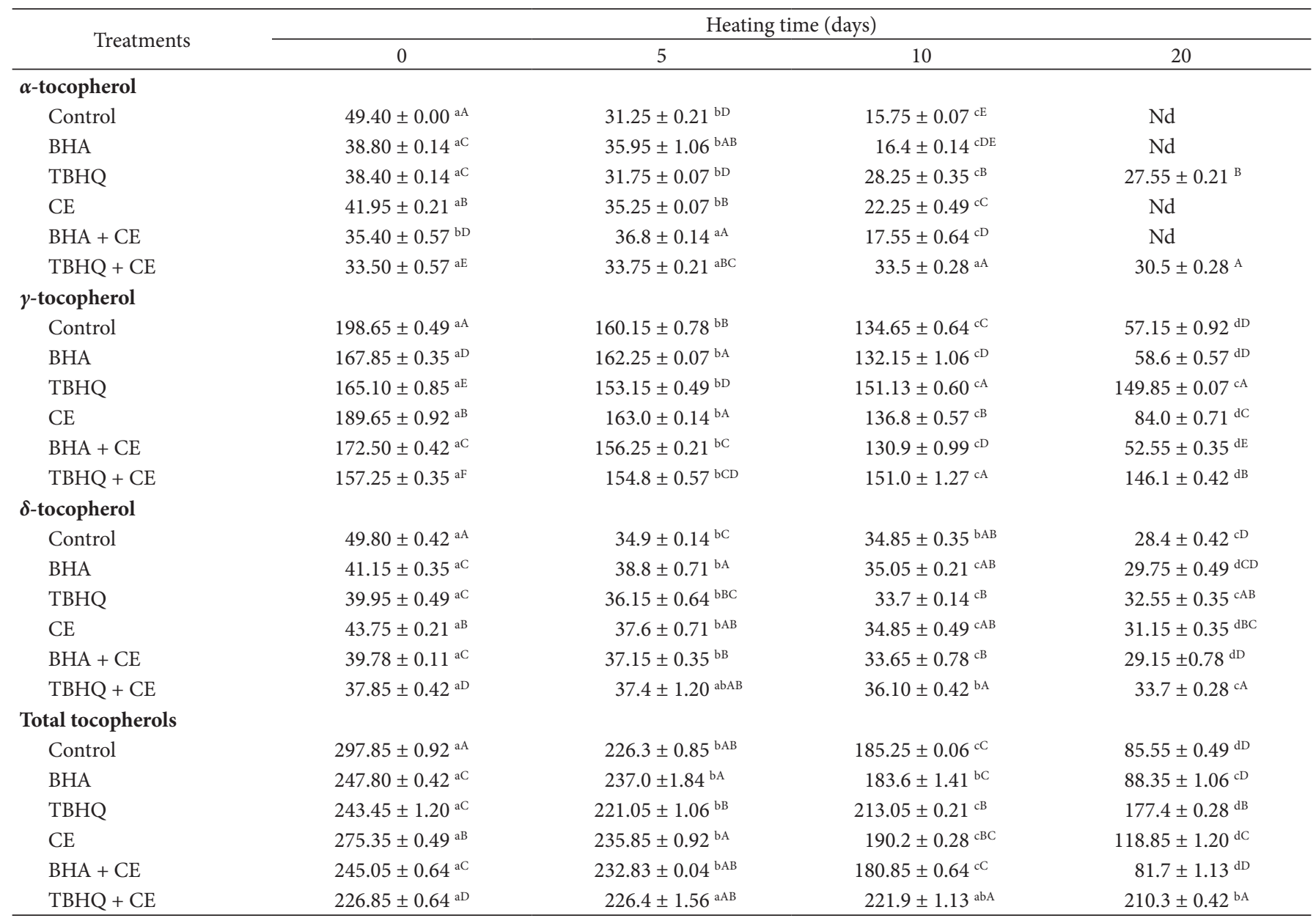

Different lowercase letters for the same treatment indicate statistical difference by Tukey ( $\leq 0.05)$. Different capital letters for the same time indicate statistical difference by Tukey $(\mathrm{p} \leq 0.05)$. For $\alpha$-tocopherol, the statistical analysis followed the t-Student test at $95 \%$ confidence between the treatments in the time 20 . Nd: not detected. 


\section{Conclusions}

From the results obtained in this study it was possible to verify that even though the TBHQ presented greater antioxidant effects, with greater efficiency in inhibiting the formation of primary lipid oxidation compounds, the addition of CE together with this synthetic antioxidant was able to maintain the oxidative stability of the oil for 20 days of storage, also providing a lower oxidation rate in terms of mass gain. On the other hand, the lyophilized coffee husk extract showed similar behavior to the antioxidant BHA in terms of stability. In addition, the BHA + CE mixture proved better at limiting increases in mass compared to the soybean oil added to BHA alone.

The synergistic effect was also observed in the retention of tocopherols by the treatment TBHQ + CE, effectively protecting all the isomers. This effect provided greater stability in the $\gamma$-tocopherol contents during the storage, presenting minimal reductions.

In conclusion, when compared to synthetic antioxidants, $\mathrm{CE}$ is capable of slowing down lipid oxidation, making it suitable for use as a natural alternative to the synthetic antioxidant BHA. In addition, the synergistic effect between CE and TBHQ made it possible to reduce the concentration of TBHQ to be applied to soybean oil, contributing to better health security.

\section{Acknowledgements}

The authors would like to express their sincerest gratitude for the financial support provided by the National Council of Technological and Scientific Development and Coordination for the Improvement of Higher Education Personnel.

\section{References}

American Oil Chemists' Society - AOCS. (1993). Official Methods and Recommended Pratices of the American Oil Chemists's Society (3th ed.). Champaign: AOCS.

American Oil Chemists' Society - AOCS. (2009). Official Methods and Recommended Practices of the American Oil Chemists' Society (6th ed.). Champaign: AOCS.

Araújo, J. M. A. (2006). Química de alimentos: teoria e prática (3. ed). Viçosa: UFV.

Brasil. Ministério da Saúde. (2005, Setembro 23). Regulamento técnico sobre a Ingestão Diária Recomendada (IDR) de proteína, vitaminas e minerais (Resolução RDC n ${ }^{\circ} .269$, de 22 de setembro de 2005). Diário Oficial [da] República Federativa do Brasil.

Gadow, A., Joubert, E., \& Hansmann, C. F. (1997). Comparison of the antioxidant activity of aspalathin with that of other plant phenols of rooibos tea (Aspalathus linearis), $\alpha$-Tocopherol, BHT, and BHA. Journal of Agricultural and Food Chemistry, 45(3), 632-638. http:// dx.doi.org/10.1021/jf960281n.

Hinneburg, I., Dorman, H. J. D., \& Hiltunen, R. (2006). Antioxidant activities of extracts from selected culinary herbs and spices. Food Chemistry, 97(1), 122-129. http://dx.doi.org/10.1016/j. foodchem.2005.03.028.

Hui, Y. H. (1996). Edible oil fat products: processing technology (5th ed.). New York: John Wiley \& Sons.
Iqbal, S., \& Bhanger, M. I. (2007). Stabilization of sunflower oil by garlic extract during accelerated storage. Food Chemistry, 100(1), 246-257. http://dx.doi.org/10.1016/j.foodchem.2005.09.049.

Jorge, N. (2009). Química e tecnologia de óleos vegetais. São Paulo: Cultura Acadêmica.

Jorge, N., \& Gonçalves, L. A. G. (1998). Aditivos utilizados em óleos e gorduras de frituras. Boletim da Sociedade Brasileira de Ciência e Tecnologia de Alimentos, 32(1), 40-47.

Moure, A., Cruz, J. M., Franco, D., Domínguez, J. M., Sineiro, J., Domínguez, H., José, N. M., \& Parajó, J. C. (2001). Natural antioxidants from residual sources. Food Chemistry, 72(2), 145-171. http://dx.doi. org/10.1016/S0308-8146(00)00223-5.

Ramalho, V. C., \& Jorge, N. (2006). Antioxidantes utilizados em óleos, gorduras e alimentos gordurosos. Quimica Nova, 29(4), 755-760. http://dx.doi.org/10.1590/S0100-40422006000400023.

Ravelli, D. (2011). Estabilidade oxidativa de óleo de soja adicionado de extratos de especiarias: correlação entre parâmetros físico-químicos e avaliação sensorial (Dissertação de mestrado). Escola Superior de Agricultura "Luiz de Queiroz", Universidade de São Paulo, Piracicaba.

Sánchez-González, I., Jiménez-Escrig, A., \& Saura-Calixto, F. (2005). In vitro antioxidant activity of coffees brewed using different procedures (Italian, espresso and filter). Food Chemistry, 90(1-2), 133-139. http://dx.doi.org/10.1016/j.foodchem.2004.03.037.

Silva, A. C., \& Jorge, N. (2012). Oxidative stability of soybean oil added to Lentinus edodes and Agaricus blazei mushrooms extracts in an accelerated storage test. Nutrition \& Food Science, 42(1), 34-40. http://dx.doi.org/10.1108/00346651211196519.

Silva, A. C., \& Jorge, N. (2014). Influence of Lentinus edodes and Agaricus blazei extracts on the prevention of oxidation and retention of tocopherols in soybean oil in an accelerated storage test. Journal of Food Science and Technology, 51(6), 1208-1212. PMid:24876658.

Singleton, V. L. \& Rossi, J. A. (1965). Colorimetry of total phenolics with phosphomolybdic-phosphotungstic acid reagents. American Journal of Enology and Viticulture, 16(3), 144-158.

Soares, S. E. (2002). Ácidos fenólicos como antioxidantes. Revista de Nutrição, 15(1), 71-81. http://dx.doi.org/10.1590/S141552732002000100008 .

Soccol, C. R. (2002). Resíduo de café: um substrato promissor para a produção industrial de bioprodutos com alto valor agregado. In EMBRAPA-CAFÉ (Org.). I Simpósio de Pesquisa dos Cafés do Brasil (v. 1, pp. 83-98). Brasília: EMBRAPA.

Venskutonis, P. R. (2013). Natural antioxidants in food systems. In B. Grzegorz (Ed.), Food oxidants and antioxidants: chemical, biological, and functional properties (Chap. 9, pp. 235-302). Boca Raton: CRC Press.

Yang, Y., Song, X., Sui, X., Qi, B., Wang, Z., Li, Y., \& Jiang, L. (2016). Rosemary extract can be used as a synthetic antioxidant to improve vegetable oil oxidative stability. Industrial Crops and Products, 80, 141-147. http://dx.doi.org/10.1016/j.indcrop.2015.11.044.

Zhang, C. X., Wu, H., \& Weng, X. C. (2004). Two novel synthetic antioxidants for deep frying oils. Food Chemistry, 84(2), 219-222. http://dx.doi.org/10.1016/S0308-8146(03)00205-X.

Zhang, Y., Yang, L., Zu, Y., Chen, X., Wang, F., Liu, F. (2010). Oxidative stability of sunflower oil supplemented with carnosic acid compared with synthetic antioxidants during accelerated storage. Food Chemistry, 118, 656-662. 